\title{
Effect of rifampicin on liver function in man
}

\author{
PHILIPPE CAPELLE, DANIEL DHUMEAUX, MICHEL MORA, GÉRARD \\ FELDMANN, AND PIERRE BERTHELOT ${ }^{1}$
}

From INSERM U-24, Hôpital Beaujon, Clichy, Département de Bactériologie et INSERM U-99, Hôpital
Henri Mondor, Créteil, France

SUMMARY Liver function and serum concentrations of rifampicin, a highly cholephilic antibiotic, have been studied after ingestion of a single dose of $600 \mathrm{mg}$ of rifampicin in 12 patients, six of them having a normal liver and six a cirrhotic, and during treatment with $600 \mathrm{mg}$ of rifampicin per day for 17 days in eight patients, four of them having a normal liver and four a cirrhotic. Rifampicin produced competition for the elimination of bilirubin and bromsulphalein by the liver. This competition, which seemed to involve mainly the uptake by the liver cell, was always rapidly reversible when treatment was discontinued. It makes it impossible, however, to interpret a bromsulphalein test during treatment with rifampicin. In the eight patients treated for 17 days, apart from the competition already mentioned, no clinical, biological, or morphological abnormalities of the liver were ascertained. But in this limited number of patients it is not possible to exclude the fact that rifampicin could provoke jaundice by idiosyncrasy in a small percentage of cases. The serum concentrations of rifampicin were higher in cirrhotic patients than in patients with normal livers, especially after one or two weeks of treatment. It is suggested that efficient blood concentrations of rifampicin would be achieved with small doses in case of previous hepatocellular insufficiency.

Rifampicin is an antibiotic derived from the family of rifamycins; it is produced by Streptomyces mediterranei and mainly used for its antituberculous action (Vall-Spinosa, Lester, Moulding, Davidson, and McClatchy, 1970). In man, this drug is eliminated in high concentration in the bile (Acocella, Mattiussi, Nicolis, Pallanza, and Tenconi, 1968; Furesz, 1969). A few cases of jaundice have been attributed to rifampicin, which often occur during the first two weeks of treatment, and seem curiously to be more frequent in France (Lesobre, Ruffino, Teyssier, Achard, and Brefort, 1969; Morère, Stain, Chauvet, Luce, and Leprovost, 1969) where they are approximately $4 \%$ of the patients treated, whereas in other countries they number approximately $1 \%$ (Lepetit, S.A., personal communication). For theoretical reasons, the similarity of the rifampicin molecule with that of the rifamycins leads one to expect that rifampicin might cause competition phenomena in the liver cell with other organic anions, such as bromsulphalein (BSP) or bilirubin (Acocella and Billing, 1965; Acocella, Nicolis, and Tenconi, 1965).

\footnotetext{
${ }^{1}$ Please address requests for reprints to: Dr Pierre Berthelot, Unité de Recherches INSERM U-99, Hôpital Henri Mondor, 94-Créteil, France.

Received for publication 8 February 1972.
}

The purpose of the present study was to compare two groups of patients, the first receiving a single dose of rifampicin, in whom eventual competition was looked for, the other receiving the drug for 17 days, the main liver tests being kept under regular observation.

\section{Methods}

INGESTION OF A SINGLE DOSE OF RIFAMPICIN Twelve male patients were studied, 42 to 72 years old. Six of them had alcoholic cirrhosis proved histologically; among these six, two had ascites. The six other patients had livers that were estimated to be normal according to clinical and biological criteria. The BSP fractional clearance was measured from four samples taken during 20 minutes following the injection of BSP (normal: 0.145 \pm 1 SD 0.015). In the 'blank' sample obtained before injection, serum concentrations of conjugated bilirubin and unconjugated bilirubin were estimated by the method of Weber and Schalm (1962) (normal: conjugated $<0.4 \mathrm{mg} / 100 \mathrm{ml}$; unconjugated $<0.8 \mathrm{mg} / 100 \mathrm{ml}$; total bilirubin $<1.2 \mathrm{mg} / 100 \mathrm{ml}$ ). A single dose of $600 \mathrm{mg}$ of rifampicin was then given orally, the patient being fasting. Fractional clearance of BSP was estimated one hour, three hours, and occa- 
sionally 24 hours after ingestion. Serum bilirubin concentration was measured after three hours. Determination of the serum concentrations of rifampicin was made one and three hours after the ingestion by an ordinary microbiological assay, based on the diffusion of the antibiotic in agar in the presence of a culture of Bacillus brevis at $\mathbf{p H ~ 7 \cdot 3 8}$. Standard curves were obtained by dissolving increasing amounts of rifampicin in normal serum. Each measurement was made in three different dishes, each containing three discs soaked in the unknown sample after appropriate dilution with $0.15 \mathrm{M}$ phosphate buffer $\mathrm{pH} \mathbf{7 \cdot 3 8}$, and three discs soaked in a standard solution.

INGESTION OF RIFAMPICIN DURING 17 DAYS This group consisted of eight male patients aged 42 to 71 years. Four of them had histologically proved cirrhosis of alcoholic origin, one without either ascites or jaundice, one with ascites, and two with ascites and mild icterus. The four other patients had normal livers according to clinical and biological criteria; in one of these four patients a liver biopsy was taken before administration of rifampicin.

Before treatment the following tests were performed: fractional BSP clearance and determination of the two bilirubin fractions by the techniques mentioned above; serum glutamic pyruvic transaminase (SGPT) by colorimetric technique (normal $<50$ U Frankel); alkaline phosphatases (normal $<2$ U Bessey); total proteins (biuret method and

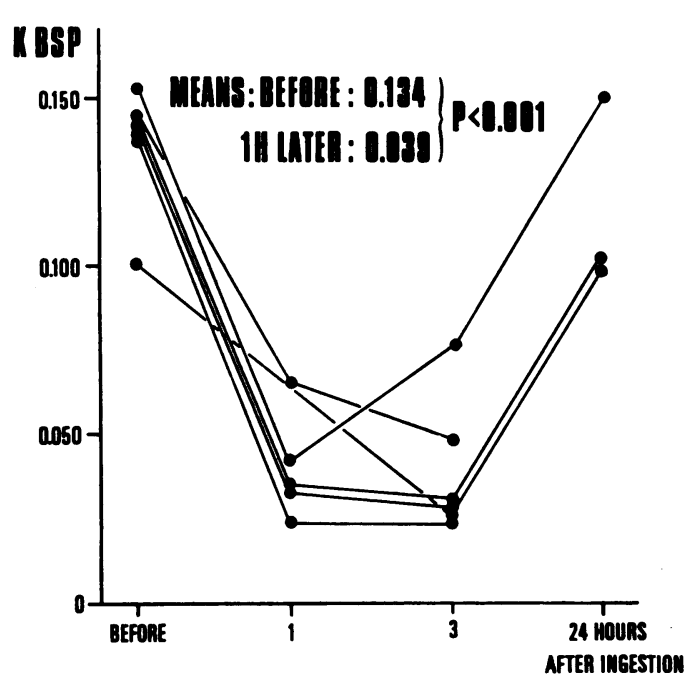

Fig. 1 Fractional clearance of BSP (K BSP) before and one $\mathrm{hr}$, three $\mathrm{hr}$, and $24 \mathrm{hr}$ after a single dose of $600 \mathrm{mg}$ of rifampicin in six patients with normal livers. electrophoresis); thymol turbidity test; blood clotting factors (laboratory of D. Ménaché, Hôpital Beaujon).

Once these examinations had been performed, a treatment of $600 \mathrm{mg}$ of rifampicin per day was started, the antibiotic being taken in a single dose, after an overnight fast. No other drug was given to any of the eight patients during the 17 days of rifampicin administration. The patients remained under daily clinical observation; liver function tests were performed and rifampicin concentrations in the serum determined after the first week of treatment and at the end. In addition, on the 17th day of treatment a liver biopsy was taken in two patients with normal livers.

\section{Results}

Except when otherwise stated, all the results are expressed as mean $\pm 1 \mathrm{SD}$. For comparison of the results, paired analysis, the Student $t$ test, or the Mann-Whitney U test were used (Siegel, 1956).

AFTER INGESTION OF A SINGLE DOSE OF RIFAMPICIN

\section{Rifampicin in serum}

One hour following the ingestion of a single dose in the six cirrhotic patients, the average serum concentration of rifampicin was $12.85 \pm 6.80 \mu \mathrm{g} / \mathrm{ml}$ as compared to $6.92 \pm 4.07$ in the patients with normal

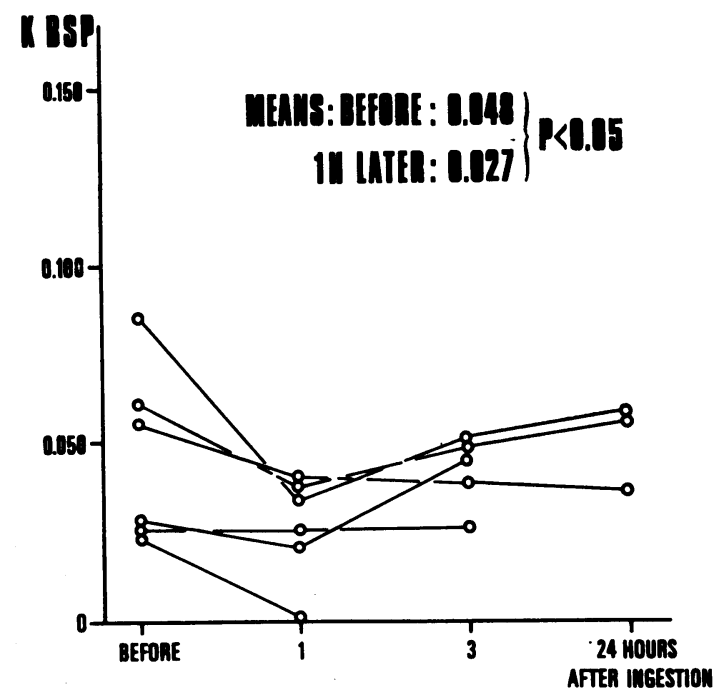

Fig. 2 Fractional clearance of BSP (K BSP) before and one $\mathrm{hr}$, three $\mathrm{hr}$, and $24 \mathrm{hr}$ after a single dose of $600 \mathrm{mg}$ of rifampicin in six patients with cirrhosis. 
livers. Probably due to the large dispersion of the results, the difference between these two figures is not significant $(0.05<\mathrm{P}<0 \cdot 10)$. After three hours the results were respectively $17.08 \pm 5.60$ for the cirrhotic patients and $10.38 \pm 3.68$ for the patients with normal livers $(\mathrm{P}<0.05)$.

\section{Fractional clearance of BSP}

In all patients, at the first hour following ingestion, there was a considerable decrease of the fractional clearance of BSP as compared with the initial figures. This was more pronounced in patients with normal livers (Fig. 1), although significant at the $5 \%$ level in the cirrhotic patients (Fig. 2). Three hours after ingestion, BSP clearance was still abnormal and a tendency to return to the initial figures was only observed 24 hours after ingestion of the antibiotic.

\section{Bilirubinaemia}

The individual results of bilirubinaemia three hours after ingestion are shown in Figs 3 and 4 in comparison with the initial values. Among the six subjects with normal livers (Fig. 3), five showed an important increase in unconjugated bilirubin, and hence of total bilirubin. The latter increased from $0.87 \pm 0.43$ $\mathrm{mg} / 100 \mathrm{ml}$ before intake of the drug to $1.51 \pm 0.90$
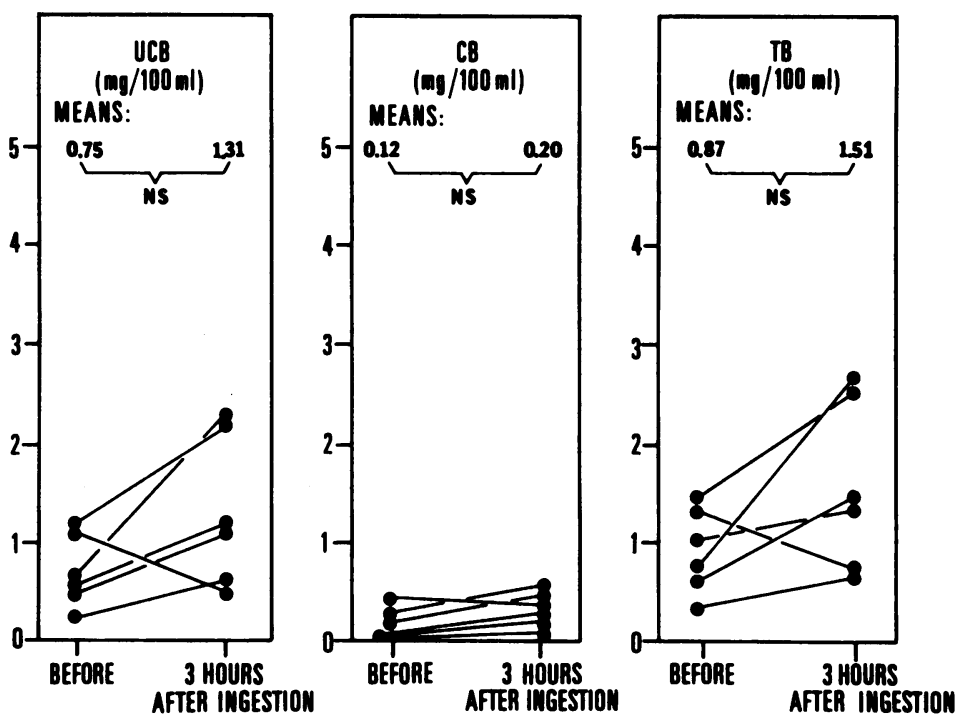

Fig. 3 Serum concentrations of unconjugated bilirubin (UCB), conjugated bilirubin $(C B)$, and total bilirubin (TB) before and three $\mathrm{hr}$ after a single dose of $600 \mathrm{mg}$ of rifampicin in six patients with normal livers.
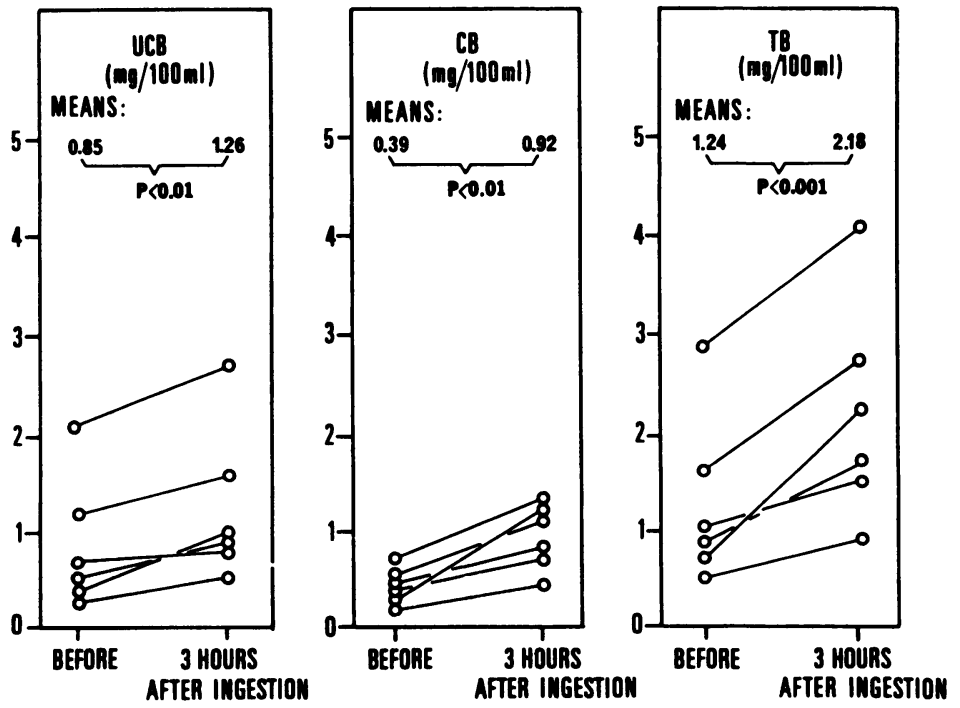

Fig. 4 Serum concentrations of unconjugated bilirubin (UCB), conjugated bilirubin $(C B)$, and total bilirubin $(T B)$ before and three $h r$ after a single ingestion of $600 \mathrm{mg}$ of rifampicin in six patients with cirrhosis. 
three hours afterwards. However, one of the subjects varied in an opposite direction to the others, and the difference was not significant within the limit of $5 \%$. In the six cirrhotic patients (Fig. 4), there was a clearer increase in the bilirubin: total bilirubin increased on an average by $75 \%$ within the three hours following ingestion of rifampicin $(P<0.001)$. It should be noted that this increase was essentially due to an increase in the unconjugated fraction but the conjugated bilirubin was also affected.

DURING AND FOLLOWING TREATMENT FOR 17 DAYS

\section{Clinical observations}

No clinical modification was noted either in patients with normal livers or in those with cirrhosis; in none of these subjects was there any sign of intolerance.

\section{Rifampicin concentrations in serum}

They were higher in cirrhotic patients than in those with normal livers. The mean of all determinations performed 24 hours after each intake of rifampicin was $1.71 \pm 2.30 \mu \mathrm{g} / \mathrm{ml}$ in the cirrhotic patients, as against $0.038 \pm 0.073$ in the group with normal livers $(U=9, P<0.002)$. The large SD observed in the cirrhotic patients could reflect the variable degree of hepatic involvement.

In the patients with normal livers, the serum concentrations of rifampicin determined at the same time following ingestion of the drug gradually decreased during treatment. On the contrary, in the cirrhotic patients the serum concentrations of rifampicin remained stable throughout the 17 days of treatment (Table I).

\section{Fractional clearance of BSP (Table II)}

In the four subjects with normal livers, in comparison with the initial figures, fractional clearance of BSP was always found to be low, and remained so throughout treatment. In the four patients with cirrhosis, the initial values were of course low; they remained so.

\section{Other data}

No significant modification was ascertained in either of the two groups of patients with regard to bilirubinaemia, SGPT, serum alkaline phosphatases, electrophoresis, or blood clotting factors. In all the patients, creatinaemia and creatinuria were within normal limits. In the two non-cirrhotic patients in whom a liver biopsy was taken on the 17th day of treatment, no abnormalities were observed under light and electron microscopy.

\section{Discussion}

A single dose of $600 \mathrm{mg}$ of rifampicin rapidly caused a considerable decrease in the BSP plasma disappearance rate and a slight increase in bilirubinaemia. Such facts suggest competition phenomena

\begin{tabular}{llll}
\hline & \multicolumn{3}{l}{ Serum Concentrations of Rifampicin $(\mu \mathrm{g} / \mathrm{ml})$} \\
\cline { 2 - 4 } & 1st and 2nd Days & 8th and 9th Days & 15th and 16th Days \\
\hline Patients with normal livers (4 subjects, 8 measurements) & $6.50 \pm 2.57^{1}$ & $3.14 \pm 0.08$ & $2.53 \pm 0.84^{1}$ \\
Patients with cirrhosis (4 subjects, 8 measurements) & $8.53 \pm 3.35^{2}$ & $8.30 \pm 5.17$ & $8.21 \pm 4.89^{2}$
\end{tabular}

Table I Serum concentrations of rifampicin eight hours after ingestion of $600 \mathrm{mg}$ per day for 17 days (mean $\pm 1 S D$ )

${ }^{1 P}<0.02$

Not significant

\begin{tabular}{|c|c|c|c|c|c|}
\hline & \multicolumn{5}{|c|}{ Clearance of $B S P$} \\
\hline & Before & & 10th Day ${ }^{2}$ & & 17th Day ${ }^{1}$ \\
\hline $\begin{array}{l}\text { Four patients with normal } \\
\text { livers }\end{array}$ & $0.105 \pm 0.060$ & $P<0.01$ & $0.054 \pm 0.023$ & Not significant & $0.041 \pm 0.009$ \\
\hline $\begin{array}{l}\text { Four patients with } \\
\text { cirrhosis }\end{array}$ & $0.040 \pm 0.018$ & Not significant & $0.028 \pm 0.009$ & Not significant & $0.033 \pm 0.038$ \\
\hline
\end{tabular}

Table II Fractional clearance of BSP before and during 17 days' treatment with rifampicin $600 \mathrm{mg}$ per day (mean $\pm 1 S D)$

${ }^{1}$ These clearances were measured $2 \mathrm{hr}$ after drug ingestion. 
as already demonstrated for other cholephilic drugs (Shotton, Carpenter, and Rinehart, 1961; Nosslin, 1963; Berthelot and Billing, 1966; Erlinger, Emond, Berthelot, Benhamou, and Fauvert, 1966; Berthelot, 1967). The first slope of BSP disappearance was mainly affected, together with an increase in unconjugated bilirubin; this last seems not to be related to any inhibition of bilirubin UDP-glucuronyl transferase activity of the liver in vitro (P. Berthelot, work in progress). One would therefore suggest that competition affects the first stage of transfer of organic anions in the liver cell, ie, uptake. Such a competition for uptake could take place on the membrane of the hepatocyte, in which case one must simply admit the existence of identical, however hypothetical, membrane carriers for rifampicin, BSP, and bilirubin. An alternative explanation is that competition for uptake would be located on cytoplasmic acceptor proteins, able to concentrate the organic anions in the hepatic cell (Levi, Gatmaitan, and Arias, 1969); for bunamiodyl and male fern extracts at least, there is substantial evidence in favour of this hypothesis (Levi et al, 1969).

The increase in serum bilirubin observed after a single dose of rifampicin affects not only unconjugated but also conjugated bilirubin especially in cirrhotic patients. This suggests that, besides the uptake defect caused by rifampicin, the last stage of hepatic disposal is impaired, ie, the biliary excretion. Such an excretion defect also exists, although only to a slight extent, for at least three drugs acting competitively on the hepatocyte: bunamiodyl (Bolt, Dillon, and Pollard, 1961; Berthelot and Billing, 1966), male fern extracts (Nosslin and Morgan, 1965), and novobiocin (Erlinger et al, 1966). As far as rifampicin is concerned, the defect in excretion is in agreement with the hypocholeretic effect which has been observed in the rat, using high doses of the antibiotic (Keberle, Schmid, and MeyerBrunot, 1969).

Competitions of the type induced by rifampicin can reasonably be considered to be functional abnormalities, directly related to the dose and always reversible when the treatment is discontinued. In no case, has there been any indication that such phenomena would be found together with any structural or ultrastructural modification. At present, it only appears to have one practical outcome: it is illusory to perform a BSP test in patients receiving this type of drug; the BSP test in a patient treated with rifampicin can only be interpreted at least 24 hours after rifampicin administration has been stopped.

In eight patients who received $600 \mathrm{mg} /$ day of rifampicin during 17 days, no changes in liver function tests were observed, except the decreased
BSP clearance. These negative results indicate that at doses of rifampicin which were given, and, apart from the competition phenomena already mentioned, there were no other direct (so-called toxic) effects on the liver in any of the patients treated. But it cannot be excluded that rifampicin may, in a small percentage of the patients treated, cause 'idiosyncratic' hepatic disorder; some positive challenges (Lees, Asgher, Hashem, and Sinha, 1970) support such hypotheses, as well as the frequency of isolated hypertransaminasaemia (Morère et al, 1969). In fact, most of the types of jaundice which have been reported appear to be mainly due to conjugated hyperbilirubinaemia. The frequency, however, of these types of jaundice is not higher than that of many other drugs (Zimmerman, 1969); such a probability can be considered to be acceptable (1) if the jaundices do not consist in pure cytolytic forms; (2) if the therapeutic efficiency of the drug is unquestionable; (3) if the drug cannot be replaced by another that involves less risk with similar therapeutic efficiency. Rifampicin seems in agreement with these criteria.

In the patients reported here, there were higher serum concentrations of rifampicin in cirrhotic patients than in patients with normal livers. This could be explained (1) by a greater digestive absorption in the cirrhotic patients; but at the present time, there is no argument to support this hypothesis; (2) by a decrease, in cirrhotic patients, of the elimination of the antibiotic by the liver. As the disposal of rifampicin seems to a certain extent similar to that of bilirubin or BSP, a poor elimination of rifampicin by the cirrhotic liver would not be surprising. In fact, the half-life of the antibiotic in the serum is longer in cirrhotic patients (Constans, Saint-Paul, Morin, Bonnaud, and Bariéty, 1969) than in subjects with normal livers (Constans et al, 1969; Verbist, 1969). Furthermore, rifampicin is metabolized in the liver by desacetylation (Furesz, 1969); a decrease of this process is conceivable in cirrhotic patients.

There was a progressive decrease in the serum concentrations of rifampicin in the patients with normal livers. This suggests a gradual induction, ie, stimulation of rifampicin metabolism by the drug itself. The results observed in the bile of patients submitted to surgical drainage of the bile ducts by T-tube seem to confirm this hypothesis: after a week's treatment with rifampicin the output of this antibiotic in the bile was higher on the eighth day than at the beginning of treatment, whereas the serum concentrations of rifampicin were lower (G. Acocella, personal communication). Moreover, such an induction would also be in accordance with the increase in paranitrophenol glucuronyl transferase activity found in patients treated with rifampi- 
cin (Hakim, Feldmann, Boucherot, Boivin, Guibout, and Kreis, 1971). The fact, however, that the cirrhotic patients do not seem to behave in a similar way remains unclear.

Theoretically, it is conceivable that jaundice induced by drugs and classified as 'idiosyncratic' is more frequent in patients in whom there is inefficient catabolism of the drug and who consequently have higher serum concentrations for the same dose administered. Hence it appears logical to advise prescription of smaller doses to patients showing preexisting modifications of their liver function tests. In addition, it would be of value to measure regularly the serum concentrations of rifampicin in patients suffering from any hepatic insufficiency, since effective concentrations can probably be achieved with fairly small doses.

We thank the Lepetit laboratories for having subsidized this study and for generously providing the rifampicin. We thank Mrs F. Nicollo and Miss A.-M. Préaux for their technical assistance, and Professor G. Acocella and Dr S. Erlinger for their constructive criticism during the preparation of the manuscript.

\section{References}

Acocella, G., and Billing, B. H. (1965). The effect of rifamycin SV on bile pigment excretion in rats. Gastroenterology, 49, 526-530.

Acocella, G., Mattiussi, R., Nicolis, F. B., Pallanza, R., and Tenconi, L. T. (1968). Biliary excretion of antibiotics in man. Gut, 9, 536-545.

Acocella, G., Nicolis, F. B., and Tenconi, L. T. (1965). The effect of an intravenous infusion of rifamycin SV on the excretion of bilirubin, bromsulphalein and indocyanine green in man. Gastroenterology, 49, 521-525.

Berthelot, P. (1967). Excretion of unconjugated bilirubin in rat bile. In Bilirubin Metabolism, edited by I. A. D. Bouchier, and B. H. Billing, pp. 189-197. Blackwell, Oxford.

Berthelot, P., and Billing, B. H. (1966). Effect of bunamiodyl on hepatic uptake of sulfobromophthalein in the rat. Amer. $J$. Physiol., 211, 395-399.
Bolt, R. J., Dillon, R. S., and Pollard, H. M. (1961). Interference with bilirubin excretion by a gall-bladder dye (bunamiodyl). New Engl. J. Med., 265, 1043-1045.

Constans, P., Saint-Paul, M., Morin, Y., Bonnaud, G., and Bariéty, M. (1969). Etude des taux plasmatiques de rifampicine et de leurs variations (440 dosages). Acta tuberc. belg., 60, 299-314.

Erlinger, S., Emond, M., Berthelot, P., Benhamou, J. P., and Fauvert, R. (1966). Effets de la novobiocine sur le fonctionnement du foie. II. Etude expérimentale. Rev. frans. Etud. clin. biol., 11, 680-686.

Furesz, S. (1969). Recent investigations on the biological properties of rifampicin. Acta tuberc. belg., 60, 266-269.

Hakim, J., Feldmann, G., Boucherot, J., Boivin, P., Guibout, P., and Kreis, B. (1971). Effect of rifampicin, isoniazid and streptomycin on the human liver: a problem of enzyme induction. [European Association for the Study of the Liver, 6th Meeting, London, 1971.] (Abstr.). Gut, 12, 761.

Keberle, H., Schmid, K., and Meyer-Brunot, H. G. (1969). The metabolic fate of rimactane in the animal and in man. In $A$ Symposium on Rimactane, pp. 20-27. Pharmaceutical Division, Ciba Ltd, Basle,

Lees, A. W., Asgher, B., Hashem, M. A., and Sinha, B. N. (1970). Jaundice after rifampicin. Brit. J. Dis. Chest., 64, 90-95.

Lesobre, R., Ruffino, J., Teyssier, L., Achard, F., and Brefort, G. (1969). Les ictères au cours du traitement par la rifampicine (12 observations). Rev. Tuberc. (Paris), 33, 393-403.

Levi, A. J., Gatmaitan, Z., and Arias, I. M. (1969). Two hepatic cytoplasmic protein fractions, $Y$ and $Z$, and their possible role in the hepatic uptake of bilirubin, sulfobromophthalein and other anions. J. clin. Invest., 48, 2156-2167.

Morère, P., Stain, J. P., Chauvet, M. C., Luce, J. P., and Leprovost, J. (1969). Essais cliniques de la rifadine (rifampicine). Rev. Tuberc. (Paris), Suppl. 33, 177-198.

Nosslin, B. (1963). Bromsulphalein retention and jaundice due to unconjugated bilirubin following treatment with male fern extract. Scand. J. clin. Lab. Invest., 15, Suppl. 69, 206-212.

Nosslin, B., and Morgan, E. H. (1965). The effect of phloroglucinol derivatives from male fern on dye excretion by the liver in the rabbit and rat. J. Lab. clin. Med., 65, 891-902.

Shotton, D., Carpenter, M., and Rinehart, W. B. (1961). Bromsulfalein retention due to administration of a gall-bladder dye (bunamiodyl). New Engl. J. Med., 264, 550-552.

Siegel, S. (1956). Nonparametric Stat istics for the Behavioral Sciences. McGraw-Hill, New York.

Vall-Spinosa, A., Lester, W., Moulding, T., Davidson, P. T., and McClatchy, J. K. (1970). Rifampin in the treatment of drugresistant Mycobacterium tuberculosis infections. New Engl.J. Med., 283, 616-621.

Verbist, L. (1969). Rifampicin blood levels in man. Acta tuberc. belg., 60, 288-298.

Weber, A. P., and Schalm, L. (1962). Quantitative separation and determination of bilirubin and conjugated bilirubin in human serum. Clin. chim. Acta, 7, 805-810.

Zimmerman, H. J. (1969). Papaverine revisited as a hepatotoxin. New Engl. J. Med., 281, 1364-1365. 